\title{
ÉTICA E ESTÉTICA EM MÁRIO DE ANDRADE
}

Tiago Hermano Breuning

Mestrando em Literatura - UFSC

Resumo: A naturalização de uma tipologia musical brasileira representativa de uma entidade nacional, pressuposta pela construção de uma tradição a partir do pensamento marioandradiano, coloca o leitor perante a aparente contraditoriedade da proposta de um sentido produzido para o aspecto sensorial por meio da palavra. O objetivo do presente trabalho consiste em analisar a valorização marioandradiana da imediaticidade funcional, com a qual emerge contraditoriamente o valor eterno do ethos. Para tanto, a incorporação da palavra pelo som se torna um aparato fundamental, mas ao contaminar o som com seu sentido, a palavra imprime a sua opacidade.

Palavras-chave: Mário de Andrade; Ethos; Anestética.

\begin{abstract}
The naturalization of a Brazilian musical typology which represents a national entity presupposed by the construction of a tradition from Mario de Andrade's thought encounters the reader with the apparent contradiction of the proposal of a sense produced to the sensorial aspect by means of the word. The aim of this paper is to analyze Mario de Andrade's valorization of the functional immediateness of the musical art, from which contradictorily the perpetual value of the ethos emerges. The incorporation of the word through sound becomes a basic apparatus, but when the sound is contaminated with its meaning, the word prints its opacity.
\end{abstract}

Keywords: Mario de Andrade; Ethos; Anaesthetics. 
Mario de Andrade compreende que a música representa "a mais desenvolvida das artes nacionais" (ANDRADE, 1976b, p. 57), de modo que "nossos compositores podem conceber normas caracteristicamente brasileiras" (ANDRADE, 1976b, p. 80), o que confere ao cancioneiro popular o que o autor denomina "entidade", o "ethos" da música nacional. Segundo Jorge Coli, o "ethos" se traduz pelo esforço social consciente do compositor. (COLI, 1998, p. 372) Na medida em que aspira a uma tradição nacional, visando "descobrir os traços psicológicos do homem brasileiro ou de tipos brasileiros" por meio da musicologia (TRAVASSOS, 1997, p. 95), Mário de Andrade contribui para a naturalização de uma tipologia musical representativa de uma entidade dotada de "fisiopsicologia" apropriada (ibid., p. 151).

O conceito a partir do qual elabora uma tradição que se inscreve na "bela continuidade nacional" consiste em uma beleza institucionalizada. Esteticamente, Mário de Andrade concebe o belo como um prazer desinteressado despertado pela empatia entre o subjetivo e o objetivo, distinguindo uma acepção geral de uma particular para o conceito. No primeiro caso, o belo se associa a uma sensação de deslumbramento, relacionado intimamente com a noção de beleza empregada nas suas variantes na fala cotidiana. No segundo caso, o belo representa, para "a Arte", o que desperta prazer, compreendido como um "sentido superior" que "se relaciona com essas regiões elevadas do espírito em que toda necessidade prática desaparece e que não alcança nenhum interesse imediato" (ANDRADE, 1995, p. 15). A respectiva concepção deriva evidentemente da filosofia kantiana, o que denuncia as matrizes do modernismo institucionalizado no Brasil.

As sensações provocadas por determinados fatores elementares, como o som, o volume, a linha e a cor, constituem sensações "puramente sensuais" (ibid., p. 15), ao passo que as sensações "mais elevadas" são organizadas pela combinação de determinados elementos. Segundo Mário de Andrade, a forma, na sua combinação de fatores elementares, fornece a sensação estética propriamente dita, de modo que o intelecto determina o que é belo. A sensação de prazer desinteressado nunca vem isolada: a percepção de um objeto produz sensações provenientes principalmente da forma e da sua universalidade. (ANDRADE, 1995, p. 17) Conclui-se que a acepção geral, ou seja, o belo enquanto o que desperta um prazer deslumbrado, relaciona-se mais intimamente com o aspecto sensorial do belo, uma vez que se associa mais com a fisiologia e menos com o intelecto. 
A propósito, ao definir o belo como "uma circunstância fisiológica" que agrada ao "ser racional" (ibid., p. 15), Mário de Andrade pretende destacar justamente que a racionalidade se associa com a fisiologia, salientando que "os prazeres fisiológicos das artes, principalmente da música são muito importantes" (ibid., p. 18). Ora, a proposta musical de Mário de Andrade, como observa Coli (1998, p. 352), "envolve relações francamente fisiológicas" que, não obstante, remetem ao fator de percepção pelos sentidos derivado da etimologia de "estética", que constitui uma forma de cognição alcançada pelos aparatos sensoriais do corpo. Ao concluir que a simultaneidade da sensação estética e da sensação de universalidade do mundo fenomenal importa para determinar o objetivo e a finalidade da arte, o autor salvaguarda a arte musical da infecundidade de determinadas teorias modernas provenientes da impossibilidade de se isolar a sensação estética do mundo fenomenal, uma vez que os fatores musicais não constituem representações. (ANDRADE, op. cit., p. 39-49) ${ }^{1}$

$\mathrm{O}$ interesse pela fisiologia da arte permanece nos artigos marioandradianos sob as formas de "dinamogenia" e de "cenestesia", relacionadas, por sua vez, ao potencial "coletivizador" ou "associativista", que atribui à música, "que de todas as artes é certamente a que mais unanimiza, mais socializa o povo". (ANDRADE, 1976b, p. 267) A música apresenta

poder dinâmico sobre o corpo, conseguindo ritmar um agrupamento humano como nenhuma arte consegue (...) capaz de socializar os homens, de fundi-los numa unanimidade, num organismo só. Isso se manifesta principalmente nas civilizações primárias em que, por assim dizer, o corpo importa mais do que a livre manifestação espiritual. (ANDRADE, apud COLI, 1998, p. 20)

Embora constate uma lacuna a "respeito das transformações da sensibilidade nos tempos da sociedade dos meios de comunicação de massa" (COLI, 1998, p. 238) por parte do interesse marioandradiano nos anos 1930, Coli reconhece que o autor elabora uma "estética da percepção" fundamentada na complexa relação da música com o ouvinte, de modo que o modernista "se incorpora a uma antiga e ilustre cadeia do pensamento musical" (ibid., p. 19). Com uma preocupação com a "responsabilidade social", no entanto, o autor se aproxima do conceito de "dinamismo do som", relacionado com a impossibilidade de percepção do som em sua "pureza" significante. A cultura demarca campos significativos 
associados com as sonoridades por meio de informações extra-musicais que se tornam constitutivas do campo musical. A incorporação da palavra se torna, portanto, um aparato fundamental: "se o ritmo 'animalizava', a palavra devolve a consciência, contaminando o som com seu sentido", tornando-a mais opaca. (ibid., p. 21)

Coli acentua a preocupação marioandradiana por um empenho "marxizante", proveniente do "artista-artesão" na dimensão internacional conferida pela Segunda Guerra. (ibid., p. 239) Segundo Coli, Mário de Andrade "indica uma nostalgia pelos tempos em que o artista, sendo em realidade um artesão da arte (...) dominava profundamente a 'técnica' exigida por sua produção", de modo que repudia a independência conquistada pelo artista moderno, exigindo que este sirva o "artefazer", objeto que deve ser produzido sempre no cotidiano, sem que se vise à sacralização. (ibid., p. 270) Assim, o conflito entre tradição nacional e internacionalismo se estabelece, de modo que "a defesa do 'nacional' se faz (...) em nome do 'popular'." Ou seja, “o 'nacional' significa a recusa do distanciamento entre música das elites (...) e a busca da transposição do fosso cavado entre o 'popular' e o 'erudito'." (ibid., p. 288)

Ao prescrever a arte como um instrumento de comunicação em contraposição ao distanciamento, Mário de Andrade valoriza a arte imediata: "a arte verdadeira é sempre um instrumento de comunicação entre os homens", uma vez que deriva de uma necessidade e de uma fatalidade do artista. "Neste sentido toda e qualquer obra de arte legítima é sempre uma obra de circunstância", afirma o autor ao conjeturar: "teremos exatamente que distinguir entre o artista gratuito e o artista participante" (ibid., p. 108-109). Ao avaliar o "resultado sensorial" produzido pela obra de um compositor do nacionalismo musical russo, Mário de Andrade considera o "poder funcional" coletivo derivado de elementos "anestéticos" que funcionam psicologicamente ao sugerir e definir a qualificação musical. (ANDRADE, apud COLI, 1998, p. 396-402) Na medida em que a obra analisada intenta uma arte erudita para uma coletividade popular, a sua lição, segundo o autor, consiste em que "o artista não tem que qualificar a massa proletária como incapaz de viver os gêneros e formas mais esteticamente refinados". O autor nega a "insensibilidade estética do homem qualquer" (ibid., p. 398), diferenciando sensibilidade e compreensibilidade. No entanto, permanece filiado a uma narrativa intimamente relacionada ao conceito marxista de ideologia: 
é preciso lembrar que as massas dominadas, entre nós, são... dominadas. $\mathrm{O}$ que quer dizer que elas não tem suficiente consciência de si mesmas, nem forças de reação para conscientizarem o seu gosto estético e suas preferências artísticas. (ibid., p. 396)

O interesse marioandradiano a "respeito das transformações da sensibilidade nos tempos da sociedade dos meios de comunicação de massa" que, segundo Coli, inexistem nos artigos dos anos 1930, transparece na medida em que a "evolução pela música mecânica" resolve a contradição entre o erudito e o popular:

postos em condição de serem explorados comercialmente e educativamente o disco, o rádio, o cinema sonoro e demais instrumentos mecânicos, eles modificaram a qualificação da música erudita, que se tornou acessível a todos. E não tenho a menor pretensão, Deus me livre! de ser o primeiro a dizer isso. (ibid., p. 397)

Mediante a popularização da arte erudita, o autor compreende que "pela primeira vez ela deixou de ser (...) um instrumento de classe e de aprimoramento educativo". Como nas civilizações da antiguidade, prevalece uma "concepção imediata e conscientemente política", ou seja, uma "momentaneidade funcional das obras". (ANDRADE, apud COLI, 1998, p. 397)

Com a condição da popularização permitida pelas tecnologias de reprodução na sociedade de massa, emerge o "valor eterno" derivado da "funcionalidade moral" do "ethos", cujo pressuposto anestético consiste em representar a sociedade. (ibid., p. 403) O "ethos" musical se apresenta, portanto, como um problema cujo pressuposto parece independente do intelecto. Afinal, o seu sentido fisiologicamente sensual, associado a “dinamizadores de massas populares", não pressupõe refinamento culto para senti-lo, assegura Mário de Andrade. O “"gozo’ artístico (não apenas estético)” se relaciona com o "valor de participação e de identificação", proveniente do conceito convencional e preliminar de "ethos" que repercute objetivamente nos elementos estruturais e nos processos da composição musical. (COLI, 1998, p. 405)

Em nome da funcionalidade da arte cujas obras concorrem para o destino da cultura brasileira (ALVARENGA, 1974, p. 43), a musicologia marioandradiana associa a arte participante ou de combate com a transitoriedade da obra de interesse imediato, a qual se revela eficaz para o "intencionismo do combate" (ibid., p. 94). Segundo Oneyda Alvarenga, 
para a musicologia marioandradiana, as atividades do artista apenas se justificam na medida em que servem aos interesses da coletividade: "Isto é, a certeza de que a obra de arte não tem apenas o destino gratuito de ser bela", mas "de contribuir para a solução de problemas vitais do seu meio e do seu tempo", sobretudo em tempos ditatoriais como os do Estado Novo, de modo que o autor valoriza a arte participante ou combativa que emprega elementos extra-musicais que permitem a inteligibilidade intelectual por meio da palavra. (ibid., p. 51-56)

Ora, ao elevar a utilidade e a transitoriedade da arte, o autor sacrifica a beleza permanente, contrariando a beleza institucionalizada. Segundo Alvarenga, o modernista concebe a beleza justamente como o instrumento de que a arte se serve: "Consciente de que a obra de arte tem sempre função social" e de que pode "servir de instrumento de distinção e opressão classista", emerge o "ethos" que aqui se expressa por meio de "normas caracteristicamente brasileiras" conscientemente empregadas pelo compositor. O "ethos" representa o valor moral que se perdeu com o surto individualista do cristianismo e da burguesia capitalista. E na medida em que compreende um pressuposto e uma sugestividade "dilapidadora do capitalismo", o "ethos" contraria o "distanciamento" purista da arte anti-ética da burguesia capitalista que opera como prova da subalternidade. (ibid., p. 96-101)

Alvarenga conclui que o autor prega justamente o retorno ao "ethos", "o dever do músico de dar um conteúdo moral à sua música e de participar, por ela, das lutas do seu tempo" (ibid., p. 97). Para tanto, Mário de Andrade prescreve "processos anestéticos que poderão dar plena funcionalidade à vagueza específica da música”, de modo que o autor “convoca os músicos a abandonarem o preconceito da intangibilidade da pureza estética do som musical e a humanizá-lo nas lutas de todos nós":

a música, pela ação psicológica e fisiológica das suas características intrínsecas, pode exercer uma influência moral, que será mais claramente determinada pelos ideais que a coletividade ligar a ela, "pelo pressuposto anestético de representar a sociedade para a qual é feita", pelo valor convencional e simbólico que, lhe sendo dado pela sociedade, "repercute objetivamente nos elementos estruturais e nos processos construtivos da composição sonora". (ibid., p. 96) 
A produção de sentido a partir apenas da palavra repercute, para o autor, na valorização da canção, "pois que a palavra e a comoção da voz humana suprem o som do sentido preciso que ela não tem" (ibid., p. 97). No entanto, a relação entre o "ethos" e os processos anestéticos se estabelece por meio das informações extra-musicais que constituem os respectivos processos.

Para tanto, corrobora o conceito marioandradiano de artesanato, na medida em que representa um corretivo do esquecimento da relação social constitutiva da obra de arte (COLI, 1998, p. 256-258), apontando para o aspecto do condicionamento social da arte evidenciado por Antonio Candido, ao frisar a proposta marioandradiana de uma arte cuja funcionalidade definitivamente humana se encontra na pesquisa do seu sentido nacional. (ibid., p. 260-262) É justamente esta capacidade da arte musical de "atingir uma especificidade técnico-estilística particular que se torna a expressão imediatamente compreensível duma ideologia qualquer e da sua aplicação social" (ANDRADE, apud COLI, op. cit., p. 402) que o autor atribui ao artista participante. No entanto, a sua proposta precisa ser problematizada:

e é mesmo refletindo sobre as funções sociais da arte (que no caso de Mário são antes psicossociais) que se pode passar a uma etapa mais profunda dos deveres do artista. Pois a reflexão sobre o problema da função social da arte não somente levaria o artista a intervir em fatores mais exteriores como a concepção do assunto, mas de um modo mais íntimo, da própria técnica. (COLI; DANTAS, in ANDRADE, 1989b, p. 30)

Mário de Andrade (1963, p. 11) postula que todo artista tem de ser ao mesmo tempo artesão, compreendendo por artesanato a parte da técnica que se pode ensinar e que se relaciona com o elemento material da arte. Com $O$ artista e o artesão, segundo Jorge Coli (op. cit., p. 234-235), "Mário de Andrade propõe um retorno (...) a 'materialidade' na arte" e, mais importante, "uma moralização do fazer artístico, uma ética do artesanato". Para Coli, o artesanato adquire uma dupla função, ou seja, "moralizar o artista, colocando-o por trás de sua produção", e possibilitar a "consciência política exigindo que ele ponha a obra a serviço do seu empenho". Portanto, a música, "a mais social das artes", é "a primeira de todas a dever submeter-se a esta exigência”, de modo que o músico deve ser sacrificado “pela política e pela consciência artesanal” (ibid., p. 23). 
Mário de Andrade relaciona o potencial fisiológico da música ao primitivismo, visto que a música atua "sobre o corpo", o que se manifesta, segundo o autor, principalmente entre os povos primitivos, para os quais o corpo assume um papel deveras importante. (ibid., p. 20) Não obstante, o conceito, enquanto designação de orientações estéticas encontrados nos povos primitivos, indica, segundo Mário de Andrade, uma "atitude mental" (ANDRADE, set. 1944, p. 23), ou seja, uma busca intencional de determinados efeitos, que apenas equivocadamente pode ser considerada primitiva. Neste sentido, o primitivismo interessa como efeito de nacionalizar as obras, por meio de uma "busca na cultura material das nossas raças", que produz fenômenos de afirmação e "repurificação nacional", derivados da busca para "reachar na fonte" os "caracteres nacionais perdidos", bem como para adquirir as "fontes nacionais insuspeitadas" (ibid., p. 23-24). ${ }^{2}$

A obra primitiva se caracteriza psicologicamente pela imitação e pelo prazer, associados a usos e interesses. O primitivo imita, em detrimento da natureza, os fatores da beleza ou do prazer, os quais dissocia do modo como se manifestam na natureza, adquirindo as noções de cor, linha, volume e som. (ANDRADE, 1995, p. 21-22) O primitivismo aponta para o desenvolvimento de certas faculdades do corpo, como a tatilidade, cujo sentido se dissocia das Belas Artes na medida em que se apresenta como insuficiente para a produção do conhecimento. (ibid., p. 30) Assim, o primitivismo marioandradiano converge aos conceitos peculiares da arte primitiva de tatilidade e de recusa da forma natural evidenciados por Carl Einstein (2002, p.56), ao associar a arte primitiva aos conceitos de movimento, forma e sensação, em detrimento da imitação realnaturalista.

Ao postular um limiar anestético na medida em que confronta o consenso sobre a percepção da arte, Carl Einstein inaugura conceitos que contrariam o prazer desinteressado assumido pelas Belas Artes. Os respectivos conceitos caracterizam a recepção da arte de massa. Em Walter Benjamin, os fatores sociais relacionados ao processo de transformação da percepção historicamente condicionada pela reprodutibilidade se associam aos movimentos de massa, cuja recepção se apresenta como distração. Para tanto, a tatilidade constitui uma forma de recepção interessada, caracterizada pela utilidade, indicada, segundo Benjamin (1994, p. 169 et seq.), para a arte, sobretudo para mobilizar as massas em momentos de crise. 
Ora, ao conceber que a transitoriedade do produto urbano implica esquecimento (COLI, 1998, p. 178-179) ${ }^{3}$, a exemplo das modinhas imperiais, cuja "função de divertir a gente" observa impressa na letra de uma modinha denominada "Chiquinha si eu te pedisse...":

Uma modinha num ai,

Distrai. (ANDRADE, 1980, p. 5)

Mário de Andrade postula que o esquecimento, bem como a passividade da atitude desinteressada, caracterizam a recepção do ouvinte por meio da distração, de modo que a canção representa "um sedativo para os nossos nervos contorcidos de tanto torcer pela esquiva Democracia” (COLI, op. cit., p. 113) e, portanto, uma anestesia.

A potencialização da arte implica, segundo o pensamento marioandradiano, sintetizar a fisiologia e o intelecto, pressupondo os processos anestéticos, compreendidos como aparatos intelectuais extra-musicais para reparar o sentido do som de sua ininteligibilidade. Para tanto, uma re-aculturação contra os limites esteticamente determinados pela arte desinteressada permite devolver a capacidade de percepção interessada, ativando a sensibilidade musical dos sentimentos sugeridos pelos sons. Nesse sentido, um personagem marioandradiano reflete sobre a música brasileira, exigindo, como observam Jorge Coli e Luiz Carlos da Silva Dantas, "o princípio de utilidade, imediato, ligado à construção de um espírito nacional de música que está se formando" (COLI; DANTAS, op. cit., p. 35): “- Mas si não deve ter uma estética, o artista deve sempre ter uma estesia. Uma estética delimita e atrofia, uma estesia orienta, define e combate.” (ANDRADE, 1989, p. 60)

Ao analisar a alienação sensorial como uma condição sensual da modernidade, Susan Buck-Morss (ago.-dez. 1996, p. 14-15) reivindica justamente o sentido de Aistitikos como perceptivo por meio do tato, o qual se inverte no decurso da era moderna na medida em que o termo se associa, em detrimento de sua etimologia, com as formas culturais determinadas pela arte. Buck-Morss compreende que o aparato sensorial do corpo se depara com o mundo prelingüisticamente. Os sentidos antecedem a significação, ao passo que a aculturação dos mesmos se estabelece apenas posteriormente, o que explica o interesse primitivista pelos sentidos, uma vez que permanecem parcialmente imunes aos efeitos da civilização. 
Não obstante, Elizabeth Travassos (1997, p. 40) argumenta que o primitivismo acentua o imediatismo e a espontaneidade e constitui uma expressão manifesta por meio de sintomas, enraizada na natureza humana e sem linguagem propriamente dita. Assim, a expressão musical dos povos primitivos difere necessariamente do prazer desinteressado da beleza, apontando para o interesse marioandradiano pela espontaneidade das formas de primitivismo compreendidas enquanto retorno a fontes nacionais. (ibid., p. 157-159) A fisiologia musical explica o movimento do ato reflexo provocado pela sensação sonora se difundindo transformada por todo o organismo, ou seja, a sensação sonora cria dinamogenias. Para tanto, os fatores musicais incentivam a motricidade, de modo que a sensação sonora se segue de gesto cujo movimento, segundo Mário de Andrade (1995, p. 38 ), o adulto reprime por preconceitos sociais que o primitivo ignora.

Mário de Andrade concebe uma inteligibilidade musical primitiva a partir da qual a arte musical se estilizou conforme as necessidades das dinamogenias humanas (ibid., p. 50), cujo significado, contudo, considera convencional. Na medida em que reafirma que a possibilidade de inteligibilidade musical parece compreendida apenas pela memória das sensações expressas pelo gesto (ibid., p. 37), o pensamento marioandradiano, considerando a tatilidade da sensação sonora (ibid., p. 31), categoria que, em Benjamin, retorna associada com a tecnologia, aponta definitivamente para a noção segundo a qual "a percepção tornase experiência apenas quando se conecta com memórias sensoriais do passado" (BUCKMORSS, 1996, p. 23). Susan Buck-Morss compreende que o "isolamento da memória do passado" insensibiliza os sentidos, de modo que "nesta situação de "crise na percepção", caracterizada pela insensibilidade que define a anestética segundo Buck-Morss, "já não se trata de educar o ouvido rude para ouvir música, mas de lhe restituir a audição" (ibid., p. 24).

Não admira que Elizabeth Travassos (1997, p. 217) afirme que Mário de Andrade “encaminhou-se para a politização da arte”. A politização da arte, segundo Benjamin (1994, p. 196), representa a resposta do comunismo ao fascismo e sua estetização da política, afirmação que se encontra na origem da releitura benjaminiana da obra de arte por BuckMorss (op. cit., p. 12). Embora lamente que determinadas formas de arte deixaram de ser elementos sociais da humanidade ao representarem inutilidades decorativas, inativas como elementos de unanimismo popular, prescrevendo a palavra para intermediar o "ethos" e os 
processos anestéticos, Mário de Andrade observa, ao reconhecer que as memórias das experiências se enfraquecem gradativamente, que as palavras constituem o meio para as "assombrações". As assombrações, ou seja, as memórias revestidas de palavras, são associadas ao passado, mas "por completo diferente de tudo quanto passou" (ANDRADE, 1976a, p. 102), distintas, portanto, das sensações do passado.

O conceito marioandradiano de primitivismo decorre da premissa de utilidade da arte, cuja produção se define pela construção de uma obra que agrada sensivelmente, de modo que a obra contribui para o processo de conhecimento, bem como age sobre a sociedade. (ANTELO, 1986, p. 101) Portanto, na mesma medida em que configura uma identidade cultural, o conceito se apresenta como elemento perturbador dos efeitos padronizadores da modernidade, contraposto aos efeitos globalizadores da racionalidade moderna. (OLMOS, 1993) Assim,

em oposição à estética desinteressada do civilizado, que aceita o real como dado, o realismo primitivista seria uma arte estridente e anticartesiana que se vincula funcionalmente à sociedade, tentando explicar a ilusão normativa da arte dominante através da desmontagem dos seus pressupostos. Seu discurso marcha a contrapelo. (ANTELO, 1996, p.98)

O conceito de artesanato compreendido como a coordenação da alma, do olhar e da mão, encontrada onde quer que a arte de narrar seja praticada (BENJAMIN, 1994, p. 211), se associa, portanto, ao conceito de artesanato compreendido, por sua vez, como a parte da técnica que se pode ensinar e que se relaciona com os elementos materiais da arte. (ANDRADE, 1963, p. 11-13) Os pensamentos benjaminiano e marioandradiano convergem, enfim, ao artesanato, cujo conceito implica uma ruptura que separa a arte do patronato, garantindo uma autonomia a partir da qual o pensamento marioandradiano particularmente concebe o artista como artesão ou cortesão.

\footnotetext{
${ }^{1}$ Ao afirmar que a "música não descreve, nem representa comoções intelectualmente apreciáveis", Mário de Andrade sugere que a manifestação musical é fisiológica, de modo que a "enorme ação da música sobre o ser físico, maior que das outras artes" permite ao autor supor que "é possível imaginar-se conjeturar-se que foi essa potência físiológica da música que lhe impediu intelectualizar-se em símbolos conscientes tal qual a palavra".

${ }^{2}$ Mário de Andrade analisa ainda o emprego do mesmo conceito para designar, por um lado, o homem préhistórico e o homem natural e, por outro, a criança, de modo que esta apresenta um "prazer interessado", associado ao jogo, ao acaso e, ao contrário daqueles, ainda não nocionou nem a sensação estética, nem a arte.
} 


\footnotetext{
${ }^{3}$ Mário de Andrade afirma ainda que "o suceder das modas" torna as músicas urbanas "sem valor prático permanente", de modo que "essas músicas são esquecidas". (ANDRADE, 1993, p. 134)

${ }^{4}$ Ana Cecília Arias Olmos observa que a presença do primitivo coloca em crise a identidade cultural ocidental, descentrando as soluções propostas pela identidade racional do Ocidente e atentando contra as homogeneizações modernas com o surgimento do Outro ou com a irrupção da diferença no Mesmo.
}

\section{REFERÊNCIAS}

ALVARENGA, Oneyda. Mário de Andrade, um pouco. Rio de Janeiro: José Olympio, 1974.

ANDRADE, Mário de. Primitivos. Revista da Academia Paulista de Letras. n. 27. São Paulo, set. 1944.

1963. O artista e o artesão. In: . O baile das quatro artes. São Paulo: Martins,

Memória e assombração. In: . Táxi e crônicas no Diário Nacional. Estabelecimento de texto, introdução e notas de Telê Porto Ancona Lopez. São Paulo: Duas Cidades, 1976a.

. Música, doce música. 2. ed. São Paulo: Martins, 1976 b.

. Modinhas imperiais. Belo Horizonte: Itatiaia, 1980.

. O banquete. 2. ed. São Paulo: Duas Cidades, 1989.

. Música e jornalismo: Diário de São Paulo. Pesquisa, estabelecimento de texto, introdução e notas de Paulo Castagna. São Paulo: Hucitec, 1993.

. Introdução à estética musical. Pesquisa, estabelecimento de texto, introdução e notas de Flávia Camargo Toni. São Paulo: Hucitec, 1995.

ANTELO, Raul. Na ilha de Marapatá: Mário de Andrade lê os hispano-americanos. Prefácio de Alfredo Bosi. São Paulo: Hucitec; Brasília: INL, Fundação Nacional PróMemória, 1986.

BENJAMIN, Walter. Obras escolhidas I: Magia e técnica, arte e política. Trad. Sérgio Paulo Rouanet. 7. ed. São Paulo: Brasiliense, 1994.

BUCK-MORSS, Susan. Estética e anestética: o "ensaio sobre a obra de arte" de Walter Benjamin reconsiderado. Travessia. n. 33. Florianópolis: UFSC, ago.-dez. 1996. 
COLI, Jorge. Música final: Mário de Andrade e sua coluna jornalística Mundo musical. Campinas: UNICAMP, 1998.

EINSTEIN, Carl. La escultura negra y otros escritos. Barcelona: Gil e Gaya, 2002.

OLMOS, Ana Cecília Arias. Políticas do primitivo: as estéticas modernistas de Mário de Andrade e Lezama Lima. Dissertação de Mestrado. Florianópolis: Curso de Pós-Graduação em Literatura da UFSC, 1993.

TRAVASSOS, Elizabeth. Os mandarins milagrosos: arte e etnografia em Mário de Andrade e Béla Bartók. Rio de Janeiro: Jorge Zahar, 1997. 